\title{
A Compact WiMAX Band-Notched UWB MIMO Antenna with High Isolation
}

\author{
Burhan AZARM ${ }^{1}$, Javad NOURINIA ${ }^{1}$, Changiz GHOBADI ${ }^{1}$, Maryam MAJIDZADEH ${ }^{2}$, Nazir HATAMI \\ ${ }^{1}$ Electrical Engineering Dept., Urmia University, Urmia, Iran \\ ${ }^{2}$ Dept. of Electrical and Computer Engineering, Urmia Girls Faculty, West Azarbaijan branch, \\ Technical and Vocational University (TVU), Urmia, Iran
}

st_b.azarm@urmia.ac.ir, j.nourinia@urmia.ac.ir, ch.ghobadi@urmia.ac.ir,mmajidzadeh@tvu.ac.ir, st_n.hatami@urmia.ac.ir

Submitted June 5, 2018 / Accepted August 23, 2018

\begin{abstract}
A multiple-input-multiple-output (MIMO) antenna is proposed for ultra-wideband (UWB) applications with high isolation capability. The proposed MIMO structure consists of two simple square monopole antennas with slotted ground plane structure with $S_{11}$ bandwidth of 2.2 to $10.8 \mathrm{GHz}$ and isolation level better than $-30 \mathrm{~dB}$. U-shaped and L-shaped slots are adopted to realize a notched band within 3.3-3.8 GHz relating to WiMAX frequency band. With the aim of enhancing the isolation between the monopole antennas, two parasitic structures are wisely embedded between the monopole antennas on backside of the substrate. The MIMO antenna prototype with a compact size of $25 \times 38 \mathrm{~mm}^{2}$ is fabricated and measured. Based on the simulation and experimental results, the proposed MIMO antenna well-performs in ultra-wideband (UWB) band-notched MIMO application.
\end{abstract}

\section{Keywords}

Monopole antennas, ultra wideband (UWB), multipleinput-multiple-output (MIMO), WiMAX bandnotched function, high isolation

\section{Introduction}

Owing to admirable merit such as capability in increasing channel capacity without requiring additional frequency spectrum or power, multiple-input-multipleoutput (MIMO) technology is attracting the attention of communication experts [1]. As the term "MIMO" implies, this communication system requires deployment of multiple antennas installed in the transmitter and/or receiver with low coupling between the constituting elements. Evidently, such a requirement could be suitably fulfilled in large systems where there is sufficient space for antenna installation. However, for portable devices with limited space, installing multiple antennas with low coupling and small size is a serious technical challenge. To overwhelm this flaw, various MIMO antennas have been explored in portable devices and different wireless systems. In this regard, Long Term Evolution (LTE), Digital Code Squelch (DCS) [2], [3], UMTS [4], [5], WiMAX/WLAN applications [6], high directional radiation properties [7], and UWB applications [8] could be named. On the other hand, UWB frequency spectrum extends from 3.1 to $10.6 \mathrm{GHz}$, assigned by the FCC for unlicensed use [21]. Moreover, some narrower frequency ranges are dedicated for other applications such as WiMAX in $3.3-3.8 \mathrm{GHz}$, WLAN in 5-6 GHz, and etc. within the UWB frequency range. The elimination of this interference is the topic of interest for relevant researches. One of the possible solutions to the mentioned problem is to design UWB antennas with bandnotched characteristic [9-13]. With the aim of benefitting from the advantages of both MIMO and band-notched antennas, band-notched MIMO antennas have become an interesting category in antenna design era. For instance, in [14] a MIMO antenna with high isolation and sharp notched band is proposed for UWB filtering applications. The two-element MIMO antenna adopts a T-shaped slot to enhance the isolation feature and an L-shaped slot to generate the notch in C-band. In [15], another MIMO antenna with G-shaped configuration is designed for use in mobile terminals. Suitable placement of the elements and accurate tuning of their dimension results in suitable band-notched performance through the G-shaped structure. In [16] a three band printed antenna is proposed for MIMO applications. Three operating frequency bands are realized by adoption of a rectangular open-ended slot combined with a rectangular strip with an inverted L-shaped open-ended slot. Through the utilization of the proposed design, WiMAX and WLAN frequency bands are covered. Another configuration with compact size mu-negative half mode composite right left handed metamaterial based antenna is proposed for MIMO applications in [17]. More than $50 \%$ size reduction and $9 \mathrm{~dB}$ more mutual coupling reduction is obtained by this antenna scheme. A brief literature review reveals that proper research studies have been conducted on design of band-notched MIMO antennas. However, the size reduction issue along with isolation increment still requires further attention and research studies. Based on the aforementioned discussion, this paper aims at proposing a novel sketch of a UWB MIMO 
antenna with band-notched characteristics in WiMAX frequency band. The proposed two-element $25 \times 38 \mathrm{~mm}^{2}$ MIMO antenna is composed of two monopole antennas with two L-shaped and U-shaped slots on their patches. Good impedance matching, high isolation throughout the UWB, and a band-notched characteristic in $3.3-3.8 \mathrm{GHz}$ are some of the features of the proposed design. Moreover, smaller size with respect to many similar designs is obtained as a marvelous feature which makes the antenna a suitable and cost-effective one especially in applications with limited space [18], [19]. Specifically speaking the main merits of the proposed design could be summarized as follows:

- Offering a small-sized antenna with small constituent elements which makes its installation and deployment easy.

- Tuning the notched band exactly on the in-service and applicable WiMAX frequency band.

- Obtaining high gain and efficiency over the operating frequency band which confirms the antenna outperformance.

The remainder of this paper is organized as follows: Section 2 addresses the antenna design process. Performance analysis of the MIMO antenna is presented in Sec. 3. Results and performance discussion are surveyed in Sec. 4. A comparison with similar designs is provided in Sec. 5. Ultimately Section 6 concludes the paper.

\section{MIMO Antenna Design}

The geometry of the proposed MIMO antenna is shown in Fig. 1(a). As mentioned earlier, the proposed MIMO structure is composed of two elements. These elements are planar monopole antennas, denoted as PM1 and PM2 in Fig. 1(b). As it is shown, each element is composed of a rectangular patch and a feed line on top layer of the substrate. A rectangular microstrip feed line with the length and width of 9 and $1.8 \mathrm{~mm}$ respectively, feeds the monopole antenna. Moreover, slotted rectangular ground plane is wisely embedded on the backside of the substrate. Two connected L-shaped and one U-shaped slot, denoted as patch slots on the radiating patch, yield band notched property achievement. Each of the monopole antennas comprise a compact size of $20 \times 10 \mathrm{~mm}^{2}$ which results in the overall MIMO antenna size of only $25 \times 38 \mathrm{~mm}^{2}$. Also, $1.6 \mathrm{~mm}$ thick FR4 substrate with relative permittivity of 4.4 and loss tangent of 0.02 is selected as the substrate. It is worth noting that when the two planar monopole antennas are arranged in the form of a two-element MIMO antenna, two parasitic elements are wisely embedded on the backside of the substrate with the aim of better isolation. Detailed dimensions of the proposed design are shown in Fig. 1 where the exact optimized values of the parameters are reported as follows: $W_{\text {sub }}=38 \mathrm{~mm}, L_{\text {sub }}=25 \mathrm{~mm}, h_{\text {sub }}=1.6 \mathrm{~mm}, W_{\mathrm{f}}=$ $1.8 \mathrm{~mm}, L_{\mathrm{f}}=9 \mathrm{~mm}, W=10 \mathrm{~mm}, W_{\mathrm{p}}=4 \mathrm{~mm}, L_{\mathrm{p}}=1 \mathrm{~mm}, W_{\mathrm{p} 1}$ $=2 \mathrm{~mm}, W_{\mathrm{g}}=12.5 \mathrm{~mm}, L_{\mathrm{g}}=5 \mathrm{~mm}, W_{\mathrm{s}}=5 \mathrm{~mm}, L_{\mathrm{s}}=7 \mathrm{~mm}$,

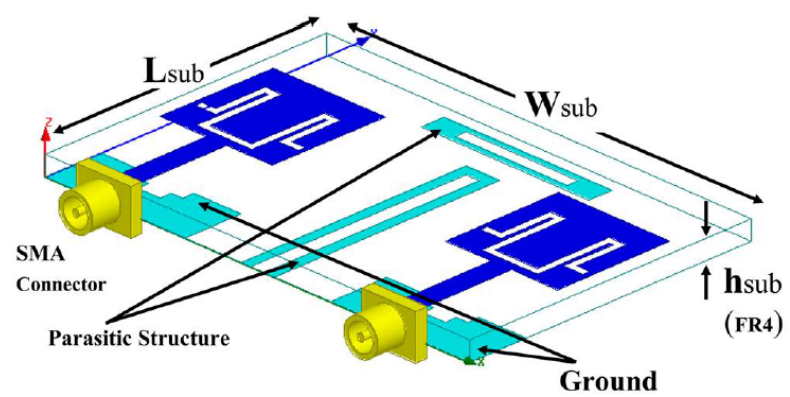

(a)

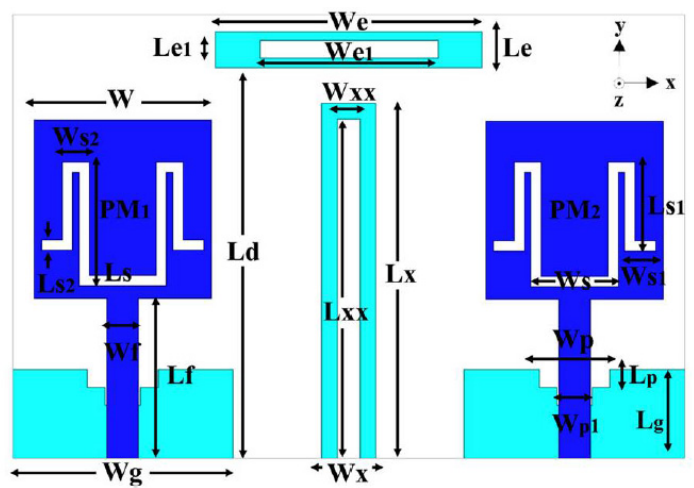

(b)

Fig. 1. Geometry of the proposed MIMO antenna: (a) side view, (b) top view.

$W_{\mathrm{s} 1}=1.8 \mathrm{~mm}, L_{\mathrm{s} 1}=5 \mathrm{~mm}, W_{\mathrm{s} 2}=1.5 \mathrm{~mm}, L_{\mathrm{s} 2}=0.6 \mathrm{~mm}$, $W_{\mathrm{x}}=3 \mathrm{~mm}, L_{\mathrm{x}}=20 \mathrm{~mm}, W_{\mathrm{xx}}=1.2 \mathrm{~mm}, L_{\mathrm{xx}}=19.1 \mathrm{~mm}$, $L_{\mathrm{d}}=22 \mathrm{~mm}, W_{\mathrm{e}}=15 \mathrm{~mm}, L_{\mathrm{e}}=2 \mathrm{~mm}, W_{\mathrm{e} 1}=10 \mathrm{~mm}$, and $L_{\mathrm{e} 1}=1 \mathrm{~mm}$.

\section{MIMO Antenna Performance Analysis}

This section investigates the proposed MIMO antenna performance. The effects of the parasitic structure, ground rectangular slots, and patch slots are discussed in detail.

\subsection{Effects of Parasitic Structure on Substrate Backside}

As mentioned earlier, parasitic structures are located on backside of the substrate to enhance the isolation between PM1 and PM2. To shed light on the effect of parasitic elements presence, the MIMO structure with and without the parasitic elements are simulated with Ansoft High Frequency Structure Simulator (HFSS) [20]. The relevant $S_{11}$ and $S_{21}$ curves are plotted in Fig. 2. It is clearly seen that wider $S_{11}$ bandwidth and significant higher isolation is obtained due to the presence of parasitic structures. As well, it is clearly seen that by the inclusion of the parasitic element, the first resonance (around $3.5 \mathrm{GHz}$ ) is shifted toward lower frequencies. This observation is directly due to the coupling effect between the included parasitic element and the other conductive elements in antenna geometry. This phenomenon yields in the bandwidth extension at lower frequencies. Also, by embedding the parasitic 


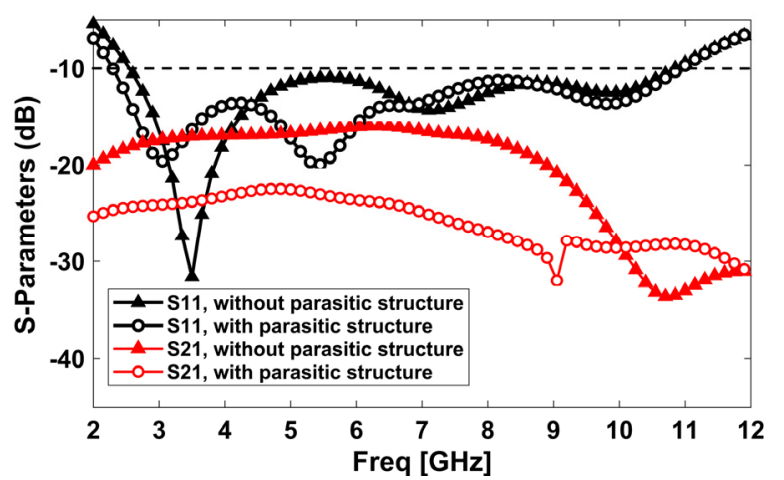

Fig. 2. S parameters of the MIMO antenna with and without parasitic structure.

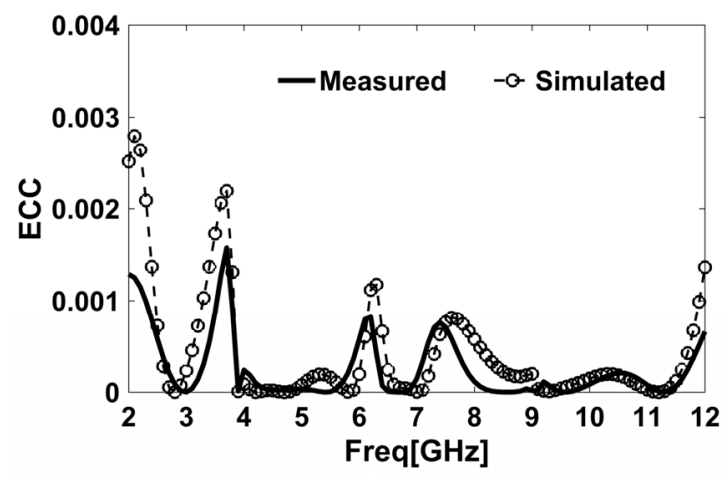

Fig. 3. ECC of the proposed MIMO antenna.

element, a new path is created for the current to flow. Hence, a new resonance is excited around $5.5 \mathrm{GHz}$. The two excited resonances are tuned such that the wide frequency band of $2.1-11 \mathrm{GHz}$ is covered by the antenna with parasitic element.

Moreover, to investigate the effect of parasitic element in more detail, simulated and measured Envelope correlation coefficient (ECC) are plotted in Fig. 3. It is worth noting that $E C C$ is obtained from (1) as follows [23]:

$$
E C C=\frac{\left|S_{11}{ }^{*} S_{12}+S_{21}{ }^{*} S_{22}\right|^{2}}{\left(1-\left|S_{11}\right|^{2}-\left|S_{21}\right|^{2}\right)\left(1-\left|S_{22}\right|^{2}-\left|S_{12}\right|^{2}\right)} .
$$

The obtained result indicates ECC less than 0.003 which is suitable for MIMO antennas applications in communication systems.

\subsection{Effects of Patch Slots (Two L-shaped and One U-shaped Slot)}

As another influential parameter, the effect of including or excluding patch slots is studied in this section. Based on the results illustrated in Fig. 4, it is inferred that without the patch slots, no notch is obtained in $\mathrm{S}_{11}$ curve, this is while; by including the slots, WiMAX frequency band is completely notched from UWB frequency range. As well, higher isolation is achieved at WiMAX frequency band.

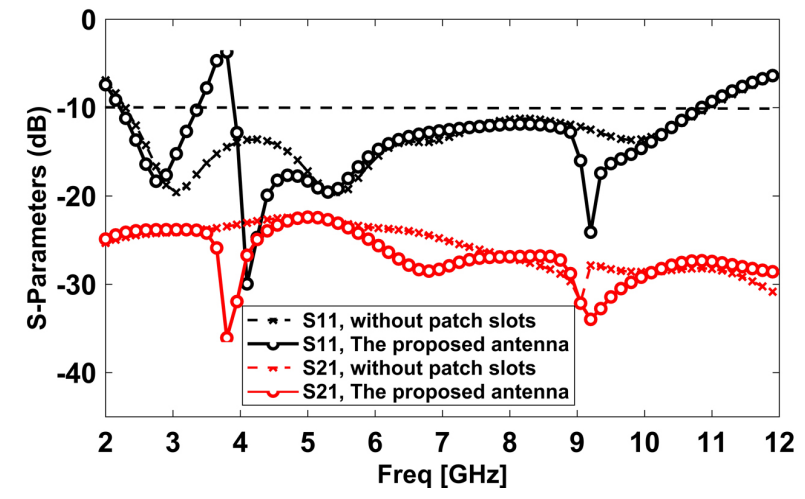

Fig. 4. S parameters of antenna with and without patch slots

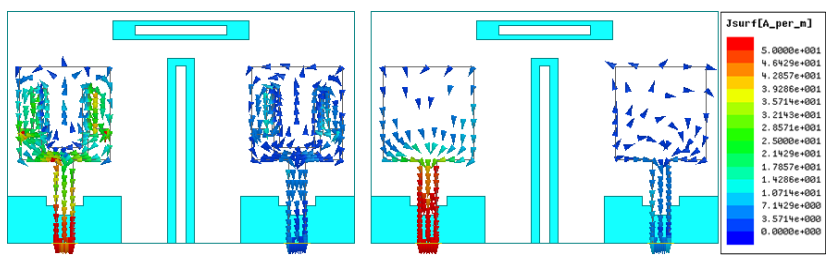

Fig. 5. Current distribution at $3.5 \mathrm{GHz}$ with and without patch slots.

The current distributions of the MIMO antennas at the notched frequency of $3.5 \mathrm{GHz}$, with and without patch slots, are shown in Fig. 5 to further discuss the issue. It can be observed that at $3.5 \mathrm{GHz}$, the current falls in opposite directions inside and outside the patch slots which is the main reason for notch realization. In fact, at the frequency of $3.5 \mathrm{GHz}$, the oppositely directed currents cancel the effect of each other; therefore, the inductance decreases and the notched frequencies are obtained.

To further analyze the effect of patch slots on the antenna performance, a parametric study is carried out. It was mentioned that the obtained notch is realized by the addition of the patch slots, hence, it is expected that the antenna performance would change if the slots dimensions are varied. As it was clearly shown in Fig. $1, L_{\mathrm{s}}$ is the arm length of the U-shaped slot on the patch. Figure 6 demonstrates the effect of changing this parameter's value on the obtained $\mathrm{S}_{11}$ curve. Four values are selected as sample values for this parameter. The results clearly indicate that as the value of $L_{\mathrm{s}}$ changes from $5 \mathrm{~mm}$ to $8 \mathrm{~mm}$ with a step of $1 \mathrm{~mm}$,

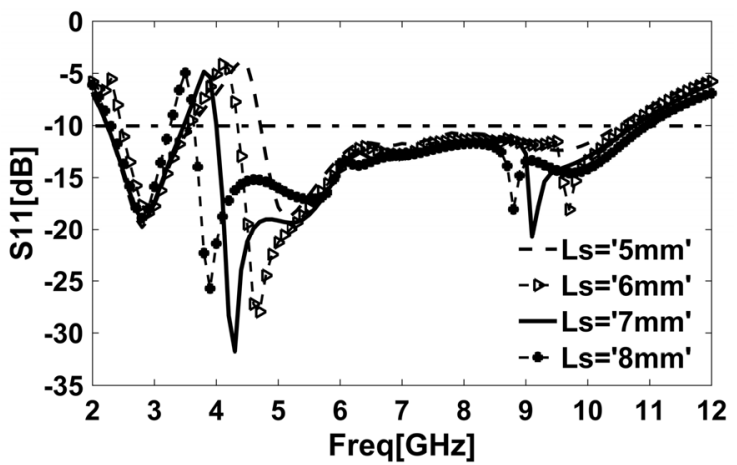

Fig. 6. The effect of changing $L_{\mathrm{s}}$ values on the MIMO antenna performance. 


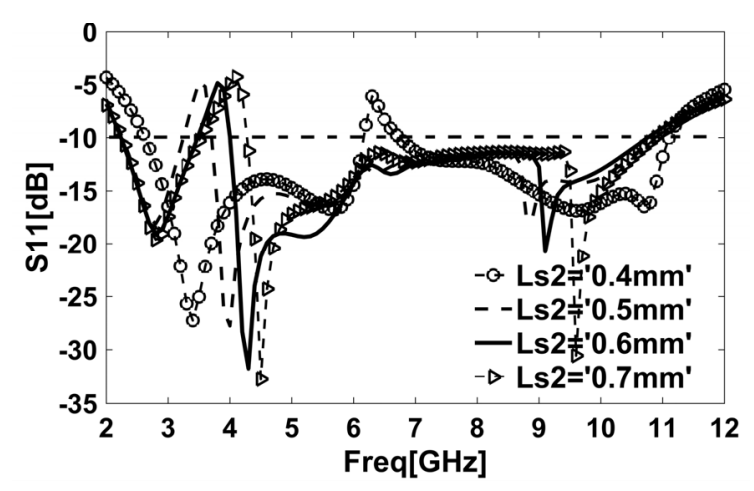

Fig. 7. The effect of changing $L_{\mathrm{s} 2}$ values on the MIMO antenna performance.

the notched band shifts toward lower frequencies. By studying the notched bands, it is seen that for $L_{\mathrm{s}}=7 \mathrm{~mm}$, the WiMAX frequency band is completely stopped by the proposed MIMO antenna. It is worth noting that as the L-shaped slots are connected to U-shaped slot, the value of $L_{\mathrm{s}}$ directly affects the dimensions of the L-shaped slots, too.

Moreover, $L_{\mathrm{s} 2}$ is the width of the L-shaped slots. The obtained results in Fig. 7 reveal that this parameter influences the antenna performance greatly. As can be seen, when the notched band is generated for $L_{\mathrm{s} 2}$ values more than $0.4 \mathrm{~mm}$. For $0.6 \mathrm{~mm}$, the WiMAX frequency band is suitably removed from the UWB frequency range.

\section{Results and Discussion}

This section establishes a platform to scrutinize the results of the fabricated prototype measurement and comparison with the simulated ones. The fabricated prototype is shown in Fig. 8. It should be noted that the $\mathrm{S}$ parameters measurement process is carried out by the PNA network analyzer E8363C in antenna and microwave laboratory [22]. Simulated and measured $S_{11}$ and $S_{21}$ curves are plotted in Fig. 9. The simulation results indicate that the antenna has an impedance bandwidth (for $S_{11}<-10 \mathrm{~dB}$ ) from $2.2 \mathrm{GHz}$ to more than $10.8 \mathrm{GHz}$ with mutual coupling (in terms of $S_{21}$ ) below $-22 \mathrm{~dB}$ at the same frequency band. Moreover, based on the simulated results, a notched band extends from $3.3 \mathrm{GHz}$ to $3.8 \mathrm{GHz}$ which suppress interference in the WiMAX band. It is worth noting that the measured notched band covers the frequency range of 3.3 to $4 \mathrm{GHz}$. Moreover, the measured $\mathrm{S}_{11}$ extends from $2.2 \mathrm{GHz}$ to $10.8 \mathrm{GHz}$ and $\mathrm{S}_{21}$ is below $-30 \mathrm{~dB}$. Although there are some differences between the simulated and measured results, but the overall performance of both simulation and measurement studies confirm each other.

Besides, antenna 3-D and 2-D radiation patterns at four sample frequencies are plotted in Figs. 10 and 11. The measured radiation patterns in Fig. 11 are obtained based on the experiments of the fabricated MIMO antenna in antenna chamber. Standard wideband horn antenna is utilized in measurement process. As it is shown in Fig. 11, four sample frequencies are selected to study the radiation patterns. The first resonance, namely $3.5 \mathrm{GHz}$, is laid in the

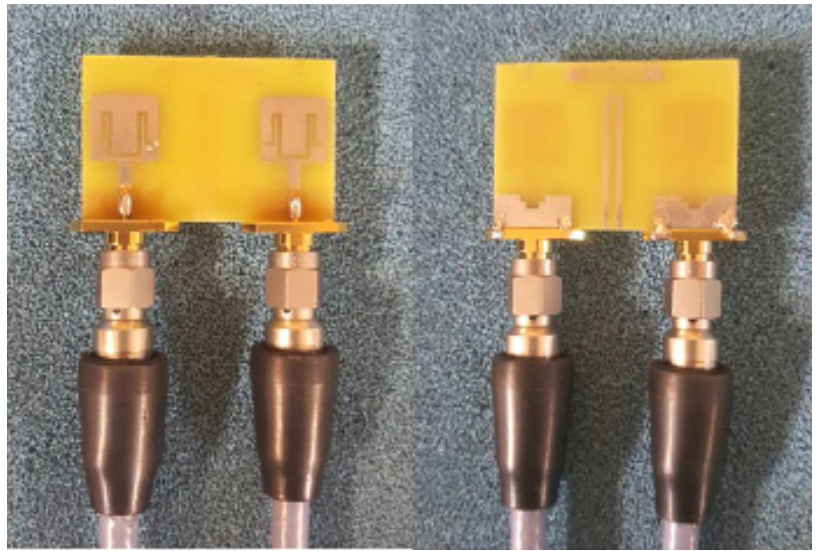

Fig. 8. Fabricated prototype.

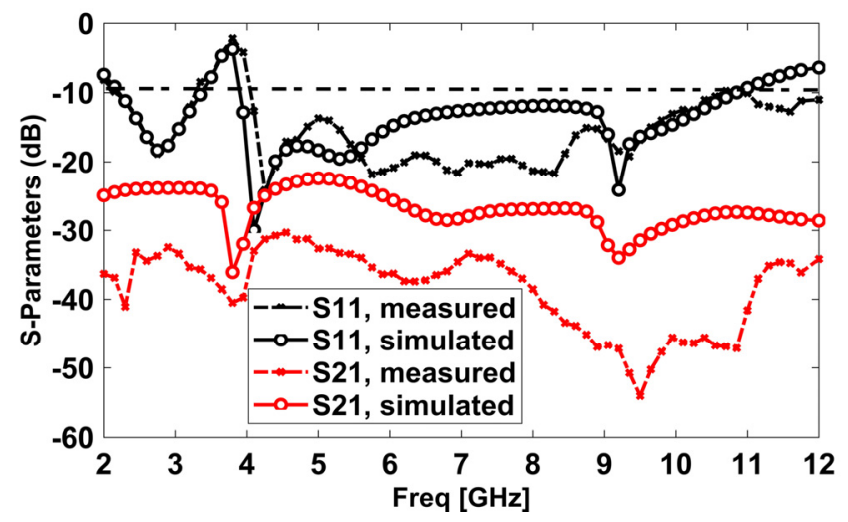

Fig. 9. Simulated and measured $S_{11}$ and $S_{21}$.

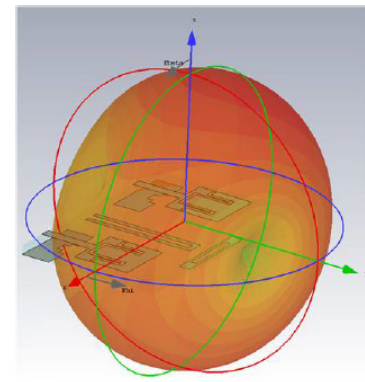

(a)

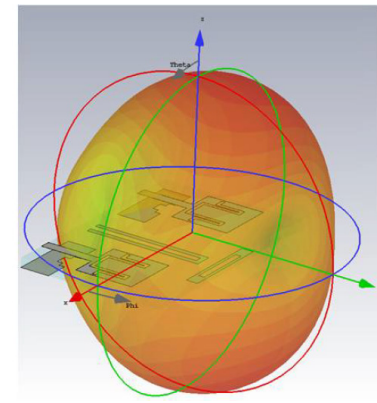

(c)

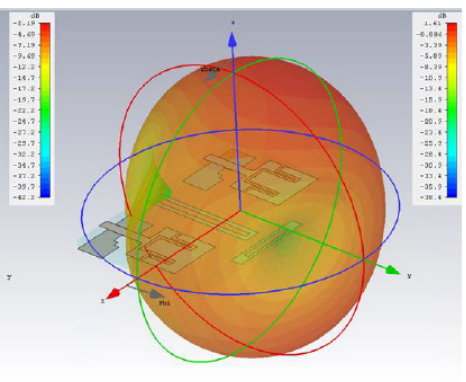

(b)

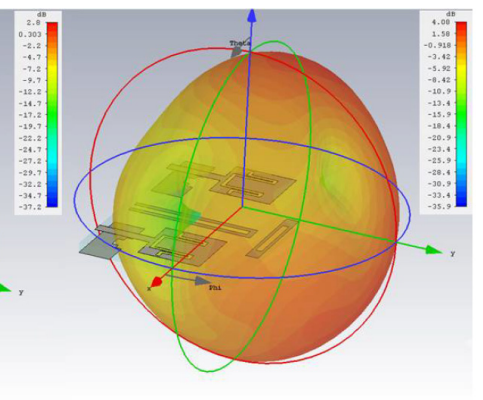

(d)
Fig. 10. 3-D radiation patterns at (a) $3.5 \mathrm{GHz}$, (b) $5.8 \mathrm{GHz}$, (c) $7 \mathrm{GHz}$ and (d) $10.5 \mathrm{GHz}$.

notched band. The results show that poor radiation pattern is obtained at this frequency which is directly due to the rejected band. Suitable radiation patterns are observed in the other three frequencies. The obtained patterns evidently 
confirm the antenna suitability for UWB communication systems and meet the requirements of MIMO antennas. Moreover, simulated and measured radiation efficiency of the proposed MIMO antenna is shown in Fig. 12. Both simulation and measurement confirm an efficiency of about $80 \%$ except for the notched band. Also, gain values are depicted in Fig. 13. It is seen that gain values vary between $1 \mathrm{~dB}$ and $4.5 \mathrm{~dB}$ over the operating frequency band. As well, reduction to negative values is obtained in the notched band which confirms the signal strong attenuation at this frequency band. In addition, the simulated and measured group delay curves over the operating frequency bands reveal the group delay variation less than 2 nanoseconds (ns). This range is acceptable in UWB communication systems.

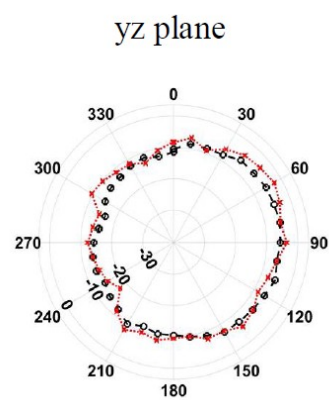

(a)
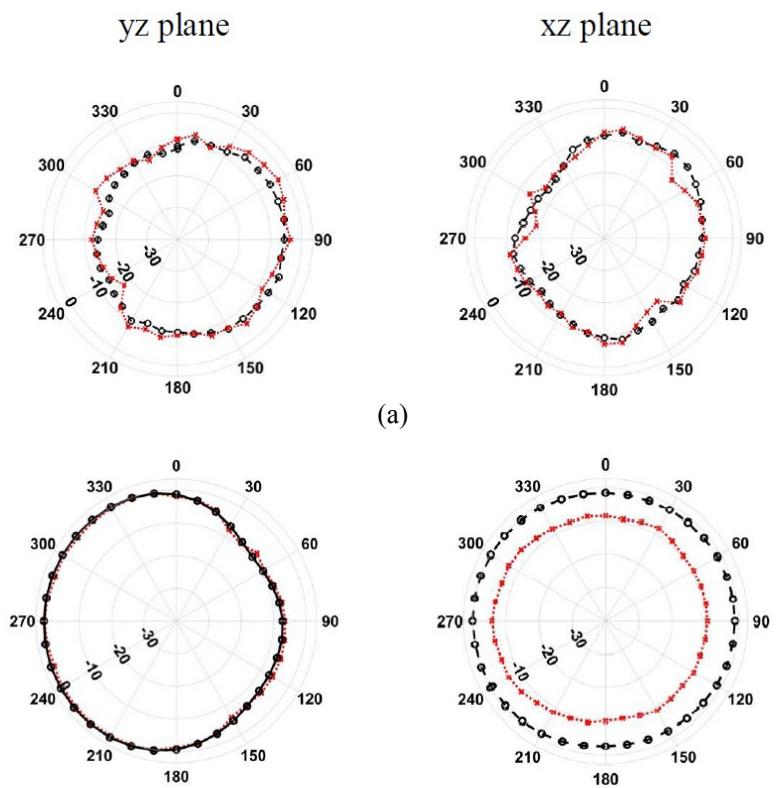

(b)
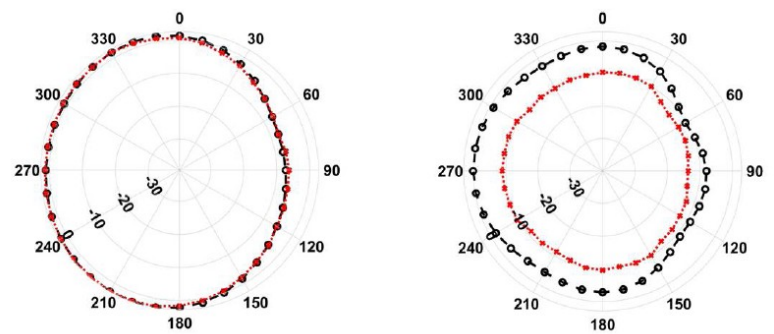

(c)
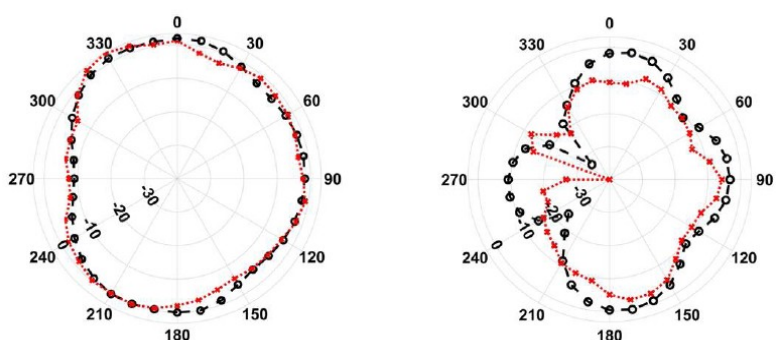

(d)

Simulated

Fig. 11. Radiation patterns of the proposed MIMO antenna at (a) 3.5 , (b) 5.5 , (c) 7 , and (d) $10 \mathrm{GHz}$.

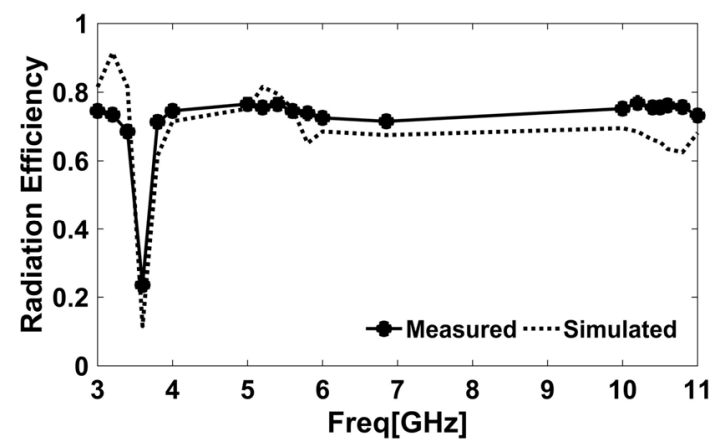

Fig. 12. Simulated and measured radiation efficiency of the proposed MIMO antenna.

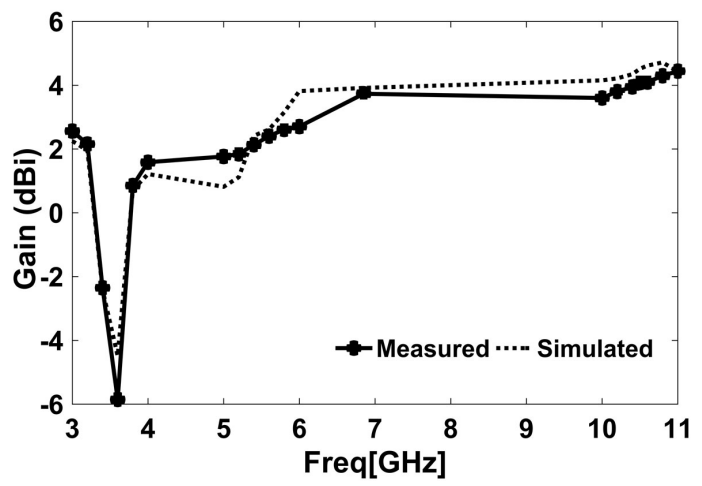

Fig. 13. Simulated and measured gain of the proposed MIMO antenna.

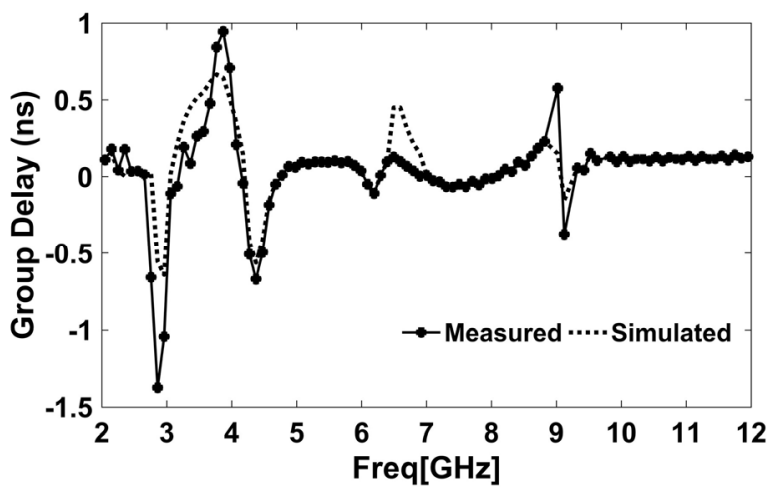

Fig. 14. Simulated and measured group delay of the proposed MIMO antenna.

It is a well-known fact that in MIMO systems, the adjacent antennas affect the performance of each other. This, in turn affects the MIMO system overall performance. Hence, apart from $\mathrm{S}_{11}$ and $\mathrm{S}_{21}$, other parameters should be studied to have a deep and precise insight of the quality of MIMO system performance. Total active reflection coefficient (TARC) is a metric which considers the adjacent antennas effect. TARC is defined as the square root of the ratio of total reflected power to the total incident power and its apparent return loss of the overall MIMO antenna system. In the case of MIMO antenna which comprises of two antenna elements, TARC is calculated as follows [23]:

$$
T A R C=\sqrt{\frac{\left(S_{11}+S_{12}\right)^{2}+\left(S_{21}+S_{22}\right)^{2}}{2}} .
$$




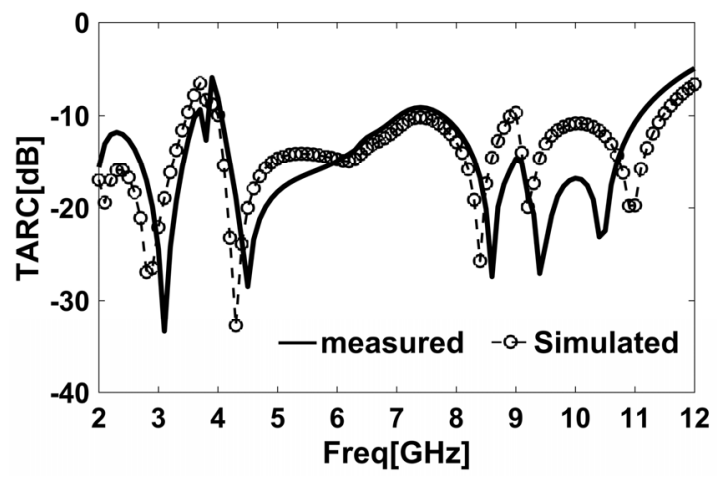

Fig. 15. Simulated and measured TARC for the proposed MIMO antenna.

TARC values lower than $0 \mathrm{~dB}$ are desired in MIMO systems. Simulated and measured TARC values are depicted in Fig. 15. It is clearly seen that suitable results are obtained in both simulation and measurement.

\section{Comparison with Other Similar Structures}

To demonstrate the advantages of the proposed design over the previous similar designs, a comparison is carried out in Tab. 1. The comparison terms include the number of elements in MIMO antennas, bandwidth, size, the obtained notched-band, and isolation. The summarized data in Tab. 1 reveals that the proposed antenna in this work is the smallest one except the antennas in [8] and [14]. However, it provides the notched band characteristic which is not achieved in [8]. Also, better isolation is obtained with respect to the antenna structure in [14]. Also, the proposed structures in [7], [11], and [15] although have larger sizes, but they offer narrower bandwidths and lower isolation between the MIMO elements. This comparison reveals the technical merits of the proposed structure over the other similar ones and satisfies the UWB band-notched requirement with high isolation.

\section{Conclusion}

A MIMO antenna with a very compact size of $25 \times 38 \mathrm{~mm}^{2}$ was designed and analyzed for portable UWB band-notched applications. The simple and cost-effective design of the proposed MIMO antenna was composed of two monopole antennas. Each of the monopoles consisted of simple slotted radiating patch and slotted ground plane. The embedded $\mathrm{L}$ and $\mathrm{U}$ shaped slots were used to generate the notched band in WiMAX frequency range. Subsequently, with the aim of enhancing the isolation between the elements, two parasitic elements were put in place between the monopole elements to reduce mutual coupling below $-30 \mathrm{~dB}$. It was shown that the achieved operation impedance bandwidth for $\left|S_{11}\right| \leq-10 \mathrm{~dB}$ of the proposed UWB MIMO antenna covers the range of 2.2 to $10.8 \mathrm{GHz}$ excluding the rejected band in $3.3-3.8 \mathrm{GHz}$. Small size,

\begin{tabular}{|c|c|c|c|c|c|}
\hline Ref & $\begin{array}{c}\text { Element } \\
\text { number }\end{array}$ & $\begin{array}{c}\text { Bandwidth } \\
(\mathrm{GHz})\end{array}$ & $\begin{array}{c}\text { Antenna } \\
\text { size }\left(\mathrm{mm}^{2}\right)\end{array}$ & $\begin{array}{c}\text { Notched } \\
\text { band }(\mathrm{GHz})\end{array}$ & $\begin{array}{c}\mathrm{S}_{21} \\
(\mathrm{~dB})\end{array}$ \\
\hline$[7]$ & 2 & $4.1-6.5$ & $50 \times 80$ & - & -17 \\
\hline$[8]$ & 2 & $3-12.4$ & $23 \times 18$ & - & -15 \\
\hline$[11]$ & 8 & $2.2-13.3$ & $50 \times 82$ & $5.1-6.1$ & -20 \\
\hline$[14]$ & 2 & $2.9-20$ & $18 \times 36$ & $3.62-4.77$ & -20 \\
\hline$[15]$ & 4 & $2.95-10.8$ & $40 \times 44$ & $4.4-6.2$ & -15 \\
\hline This work & 2 & $2.2-10.8$ & $25 \times 38$ & $3.3-3.8$ & -30 \\
\hline
\end{tabular}

Tab. 1. Summary of the characteristics of the proposed antennas and some previously designed structures.

wide bandwidth, and simple structure were named as some of the merits of the proposed design. Besides, close agreement was achieved between the simulated and measured results which nominate the proposed MIMO antenna as a suitable one for portable UWB MIMO applications.

\section{References}

[1] ZHENG, L., TSE, D.N.C. Diversity and multiplexing: a fundamental tradeoff in multiple-antenna channels. IEEE Transactions on Information Theory, 2003, vol. 49, p. 1073-1096. DOI: 10.1109/TIT.2003.810646

[2] YANG, Y., CHU, Q., MAO, CH. Multiband MIMO antenna for GSM, DCS and LTE indoor applications. IEEE Antennas and Wireless Propagation Letters, 2016, vol. 15, p. 1573-1576. DOI: 10.1109/LAWP.2016.2517188

[3] ZHANG Y., WANG, P. Single ring two-port MIMO antenna for LTE applications. Electronics Letters, 2016, vol. 50, p. 998-1000. DOI: $10.1049 / \mathrm{el} .2016 .0857$

[4] LI, Z., DU, Z., TAKAHASHI, M., SAITO, K., ITO, K. Reducing mutual coupling of MIMO antennas with parasitic elements for mobile terminals. IEEE Transactions on Antennas and Propagation, 2012, vol. 60, no. 2, p. 473-481. DOI: 10.1109/TAP.2011.2173432

[5] CHENG, C. M, CHEN, W. S., LIN, G. Q., CHEN, H. M. Four antennas on smart watch for GPS/UMTS/ WLAN MIMO application. In International Conference on Computational Electromagnetics (ICCEM). Kumamoto (Japan), 2017, p. 346-348. DOI: 10.1109/COMPEM.2017.7912744

[6] KHAN, A. A., JAMALUDDIN, M. H., AQEEL, S., et al. Dualband MIMO dielectric resonator antenna for WiMAX/WLAN applications. IET Microwaves, Antennas and Propagation, 2017, vol. 11, no. 1, pp. 113-120. DOI: 10.1049/iet-map.2015.0745

[7] JEHANGIR, S. S., SHARAWI, M. S. A miniaturized UWB biplanar Yagi-like MIMO antenna system. IEEE Antennas and Wireless Propagation Letters, 2017, vol. 16, p. 2320-2323. DOI: 10.1109/LAWP.2017.2716963

[8] TAO, J., FENG, Q. Compact ultrawideband MIMO antenna with half-slot structure. IEEE Antennas and Wireless Propagation Letters, 2017, vol. 16, p. 792-795. DOI: 10.1109/LAWP.2016.2604344

[9] AZARM, B., GHOBADI, C., NOURINIA, J., et al. A bandnotched square monopole antenna designed for bandwidth enhancement in UWB applications. Applied Computational Electromagnetics Society (ACES) Journal, 2017, vol. 32, no. 10, p. 929-934.

[10] LEE, C. H., WU, J. H., HSU, C. I. G., CHAN, H. L., CHEN, H. H. Balanced band-notched UWB filtering circular patch antenna with common-mode suppression. IEEE Antennas and Wireless Propagation Letters, 2017, vol. 16, p. 2812-2815. DOI: 10.1109/LAWP.2017.2748279 
[11] CHEN, W. X., LEE, C. H., HSU, C. I. G. CM suppression enhancement for balanced band-notched UWB closed-aperture antenna. Electronics Letters, 2017, vol. 53, no. 19, p. 1291-1292. DOI: $10.1049 / \mathrm{el} .2017 .2271$

[12] KUNDU, S., JANA, S. K. Leaf-shaped CPW-fed UWB antenna with triple notch bands for ground penetrating radar applications. Microwave and Optical Technology Letters, 2018, vol. 60, no. 4, p. $930-936$. DOI: $10.1002 /$ mop. 31075

[13] KUNDU, S. Balloon-shaped CPW fed printed UWB antenna with dual frequency notch to eliminate WiMAX and WLAN interferences. Microwave and Optical Technology Letters, 2018, vol. 60 , no. 7, p. 1744-1750. DOI: 10.1002/mop.31230

[14] CHANDEL, R., GAUTAM, A. K. Compact MIMO/diversity slot antenna for UWB applications with band-notched characteristic. Electronics Letters, 2016, vol. 52, no. 5, p. 336-338. DOI: 10.1049/el.2015.3889

[15] TOKTAS, A. G-shaped band-notched ultra-wideband MIMO antenna system for mobile terminals. IET Microwaves, Antennas and Propagation, 2017, vol. 11, no. 5, p. 718-725. DOI: 10.1049/iet-map.2016.0820

[16] ZANG, J., WANG, X. A compact tri-band printed antenna for MIMO applications. Radioengineering, 2015, vol. 24, no. 2, p. $462-469$. DOI: $10.13164 / \mathrm{re} .2015 .0462$

[17] ABDALla, M. A., IBRAHIM, A. A. Simple mu-negative half mode CRLH antenna configuration for MIMO applications. Radioengineering, 2017, vol. 26, no. 1, p. 45-50. DOI: $10.13164 / \mathrm{re} .2017 .0045$

[18] TANG, T. C., LIN, K. H. An ultrawideband MIMO antenna with dual band-notched function. IEEE Antennas and Wireless Propagation Letters, 2014, vol. 13, p. 1076-1079. DOI: 10.1109/LAWP.2014.2329496

[19] LIU, Y. Y., TU, Z. H. Compact differential band-notched steppedslot UWB-MIMO antenna with common-mode suppression. IEEE Antennas and Wireless Propagation Letters, 2016, vol. 16, p. 593-596. DOI: 10.1109/LAWP.2016.2592179

[20] Ansoft High Frequency Structure Simulation (HFSS). ver. 15

[21] FEDERAL COMMUNICATIONS COMMISSION, Washington, D.C. 20554. First Report and Order. 118 pages. [Online] Cited 2001-10-16.

[22] https://literature.cdn.keysight.com/litweb/pdf/5989-7606EN.pdf

[23] CHANDEL, R., GAUTAM, A. K., RAMBABU, K. Tapered fed compact UWB MIMO-diversity antenna with a dual band-notched characteristics. IEEE Transactions on Antennas and Propagation, 2018, vol. 66, no. 4, p. 1677-1684. DOI: 10.1109/TAP.2018.2803134

\section{About the Authors ...}

Burhan AZARM was born on 1992 in Iran. He received the B.Sc. degree in Power Engineering from the Islamic Azad University, Urmia, Iran. He is currently working toward the M.Sc degree in RF and Microwave Engineering at Urmia University. His research interests include antennas, microwave, and electromagnetics.

Javad NOURINIA received his B.Sc. in Electrical and Electronic Engineering from Shiraz University and M.Sc. degree in Electrical and Telecommunication Engineering from the Iran University of Science and Technology, and Ph.D. degree in Electrical and Telecommunication from the University of Science and Technology, Tehran, Iran in 2000. Since 2002, he has been in the Faculty of the Department of Electrical Engineering as Assistant Professor from 2002 to 2006, Associate Professor from 2007 to 2012, and Full Professor since 2013. He has been a Head of the Faculty Engineering Department from 2013 to 2017 and a distinguished professor at Urmia University. Moreover, he has been included in the Top One Percent of the World's Scientists and Academics according to Thomson Reuters' list in 2016. His research interests include small antennas, filters, MIMO antennas, periodic structures, optimization, and measurement.

Changiz GHOBADI received his B.Sc. in Electrical Engineering-Electronics and M.Sc. degrees in Electrical Engineering-Telecommunication from Isfahan University of Technology, Isfahan, Iran and Ph.D. degree in ElectricalTelecommunication from the University of Bath, Bath, UK in 1998. He is currently a professor in the Department of Electrical Engineering of Urmia University, Urmia, Iran. He established the Northwest Antenna and Microwave Research Laboratory (NAMRL) at the University of Urmia with the focus on Microwave, Antennas and Propagation devices characterization, design and fabrication. He has been included in the Top One Percent of the World's Scientists and Academics according to Thomson Reuters' list in 2017. His primary research interests are in antenna design, radar and adaptive filters.

Maryam MAJIDZADEH was born in 1987 in Urmia, Iran. She received her B.Sc. in Electrical Engineering-Electronics from Urmia University in 2009. Then, she received her M.Sc. and Ph.D. degrees in Electrical Engineering-Communication from the same university in 2012 and 2016, respectively. She is now an Assistant Professor in the Department of Electrical and Computer Engineering, Urmia Girls Faculty, West Azarbaijan branch, Technical and Vocational University (TVU), Urmia, Iran. Her research interests include antenna design, antenna miniaturization techniques, frequency selective surfaces, electromagnetic compatibility, MIMO antennas, and filters.

Nazir HATAMI NOVI was born on 1991 in Iran. He received the B.Sc. degree in Telecommunication Engineering from the Islamic Azad University, Urmia, Iran. He is currently working toward the M.Sc degree in RF and Microwave Engineering at Urmia University. 